\title{
Interpersonal Violence Among Immigrants in Portugal
}

\author{
Sónia Dias $\cdot$ Sílvia Fraga $\cdot$ Henrique Barros
}

Published online: 23 May 2012

(C) Springer Science+Business Media, LLC 2012

\begin{abstract}
To assess prevalence of interpersonal violence among a mixed gender sample of immigrants in Portugal, describing the type of violence and associated factors. A cross-sectional study was conducted between October 2008 and May 2009, evaluating a sample of 702 immigrants residing in the Lisbon region. Information was obtained by trained interviewers using a structured questionnaire. Overall, $15.1 \%$ (15.5\% females and $14.7 \%$ males; $p=0.844$ ) of the immigrants reported to be victims of at least one episode of violence during the last year, regardless of which type of violence was involved. The prevalence of intimate-partner violence was $4.1 \%$, and it was significantly higher among women than men $(7.1 \%$ vs. $0.9 \%$, respectively, $p<0.001)$. Women who reported being victims of violence during the previous year stated that the episodes occurred more often at home $(54.4 \%)$ with the partner as the perpetrator $(43.9 \%)$. On the other hand, male victims stated that the violent episodes occurred mostly in public spaces $(40.8 \%)$; men indicated that the perpetrator was frequently a stranger $(28.6 \%)$ or a co-worker $(18.4 \%)$. Violence is a frequent problem among
\end{abstract}

\author{
S. Dias $(\bowtie)$ \\ Instituto de Higiene e Medicina Tropical \& \\ CMDT - Universidade Nova de Lisboa, Lisboa, \\ Portugal \\ e-mail: sfdias@ihmt.unl.pt \\ S. Fraga $\cdot$ H. Barros \\ Institute of Public Health-University of Porto (ISPUP), \\ Porto, Portugal \\ e-mail: silfraga@med.up.pt \\ S. Fraga $\cdot$ H. Barros \\ Department of Clinical Epidemiology, Predictive Medicine \\ and Public Health, University of Porto Medical School, \\ Porto, Portugal
}

both female and male immigrants living in Portugal, with different gender patterns regarding the perpetrators and settings of abuse.

Keywords Interpersonal violence $\cdot$ Migrants $\cdot$ Portugal

\section{Introduction}

Immigrants are at risk of experiencing multiple types of violence [1-5], and different life events during the immigration process, both in the departure and host countries, potentiate such violent experiences. In the host country, an important issue is that many immigrants do not have access to information about legal immigration channels for work purposes, and some may fall prey to traffickers and exploitation [2]. Violence and discrimination in the public sphere is also a concern since acts of violence may be perpetrated by employers or by members of the general population, and occasionally by state officials involved in the immigration cycle [6].

Studies that address interpersonal violence among immigrant populations tend to focus the immigrant's vulnerability in the work place $[7,8]$, with some studies mainly addressing the particular fragile situation of female workers [3-5].

Studies dealing with intimate partner violence among immigrants tend to focus on data evaluating female victims [9-12], although a few studies have taken into account male victims and provided evidence for gender differences concerning this form of violence [13, 14].

Several samples of immigrant people provided descriptions of interpersonal violence committed by community members or family members. It has been documented that when immigrants seek help, they sometimes 
encounter a system that is not aware of their legal rights which leads them avoiding contact with the appropriate official structures [15, 16]. Indeed, in Portugal, although immigrants are entitled to health-care regardless of legal status, communities still point out several difficulties in accessing and utilizing health services [17].

When living under the constraints of their irregular immigration status, victims are particularly afraid of being sent back to their countries of origin. They are also often simply not able to face bureaucratic procedures. Another problem is that victims do not want to deal with situations that conflict with their job duties [16], especially when their employment is precarious.

We aimed to assess prevalence of interpersonal violence among a mixed gender sample of migrants that live in Portugal, describing its type and associated factors.

\section{Methods}

A cross-sectional study was conducted between October 2008 and May 2009 using a sample of 702 immigrants (52.4\% women) from Brazil, Portuguese-speaking African countries and Eastern European countries living in the Lisbon region, which has the highest concentration of immigrant population in the country. Recent official data estimate that $43 \%$ of the immigrant population in Portugal (approximately 196800 immigrants) resided in the Lisbon region in 2009 [18].

Participants were selected through snowball sampling [19]. This method involves identifying an initial number of subgroup members from whom the desired data are gathered and who then serve as 'seeds' to help identify other potential participants to be included in the sample. These individuals in turn are asked to provide information on other subgroup members, and the process continues until a target sample size has been reached [20]. The use of the snowball sampling method was due to the fact that the information available on the immigrant population in Portugal does not allow for constructing sampling frames for representative population-based surveys. Furthermore, snowball sampling allows access to participants who otherwise would be difficult or impossible to locate or contact, like undocumented immigrants [21]. Indeed, this method is recognized as being feasible to use when attempting to study hard-to-reach populations [19, 20].

In this study, representatives of non-governmental organizations (NGOs) of African, Brazilian and Eastern European immigrants were contacted by the research team and invited to participate. The researchers organized several meetings with NGOs members to present the research objectives and procedures and to request their collaboration in publicizing the study within the immigrant community and in identifying and recruiting potential participants. The inclusion criteria were being an immigrant-defined as a non-national person who immigrated for settlement purposes [22] and being 18 years or older. These potential participants were approached and invited to participate. After completing the questionnaire subjects were asked to identify and recruit other possible participants, who met the study criteria within their social networks. Questionnaires were administered by trained interviewers and trained interviewers were prepared to perform bilingual interviews when needed. Anonymous participation was guaranteed, and oral informed-consent was obtained. No financial assistance, compensation or incentives were provided to participants.

The questionnaire included closed-ended questions on individual characteristics and violence experiences.

The individual characteristics included the immigrant's age (years), education (years of completed school), region of origin, marital status, employment status (employed vs. unemployed), self-perceived income, immigration status (legal; in process of regularization or undocumented), length of stay in Portugal (years), and substance use (tobacco, alcohol and illegal drugs). The country of origin response options included a list of countries which were subsequently aggregated into the following regions: "Brazil", "Africa" (Portuguese-speaking African countries) and "Eastern Europe". Self-perceived income was assessed through the question: Do you consider that your household income is very insufficient, insufficient, sufficient or more than sufficient? In the final analysis we collapsed that variable into two categories: "insufficient" when income was classified very insufficient or insufficient; and "sufficient" when classified sufficient or more than sufficient.

Violence was assessed based on the answer to the question: "During the last year were you a victim of physical, sexual or emotional violence?" If participants answered yes, there was a set of options that they had to choose indicating where the episodes occurred, the offender, and the type of violent act. The type of violent act allowed us to identify the type of violence and to classify it as emotional (e.g. threats of abuse, humiliation, etc.), physical (e.g. slapping, pushing, kicking, bruises, injuries, using of weapons) or sexual (e.g. sexual harassment, sexual assault, etc.). In the case of the offender being the partner, the episode was considered as intimate-partner violence.

The study was approved by the Ethical Committee of the Institute of Hygiene and Tropical Medicine, New University of Lisbon.

A descriptive analysis was performed. The Chi-square test was used to assess the statistical association between violence and the independent exposure variables. The software used for data analysis was SPSS ${ }^{\circledR}$ 18.0. 


\section{Results}

During the past year, $15.1 \%$ (15.5\% females and $14.7 \%$ males; $p=0.844$ ) of immigrants reported that they were victims of at least one episode of violence, regardless of its type. We found no statistically significant gender differences in the frequency of violence in our sample of immigrants (Table 1). The prevalence of intimate partner violence for the total sample was $4.1 \%$; females reported it significantly more often than males $(7.1 \%$ vs. $0.9 \%$, $p<0.001)$. However when analyzing the prevalence of intimate partner violence by region of origin, these gender differences only reached a level of statistical significance among African immigrants (female victims $8.4 \%$ vs. $0 \%$ male victims). While the data showed differences by gender in the other populations, the level did not rise to statistical significance. The data for the other regions was Brazilians: $5.6 \%$ vs. $1.4 \%$; Eastern Europeans: $6.0 \%$ vs. $1.6 \%$, female and male victims, respectively.

Among females who reported being victims of violence during the past 12 months, $54.4 \%$ mentioned that the episode occurred at home and $43.9 \%$ indicated their partner as the perpetrator (Table 2). In contrast, $40.8 \%$ of male victims mentioned public spaces as the setting where the episode occurred, and $26.5 \%$ mentioned the home. Males indicated more frequently a stranger $(28.6 \%)$ or a co-worker $(18.4 \%)$ as the perpetrator (Table 2). Of those who were victims of violence, $34.5 \%$ of females and $28.9 \%$ of males required subsequent medical care.

The length of stay in Portugal was significantly associated to the occurrence of physical violence among women (Table 3). In males, victims of violence were more frequently smokers (15.0\% vs. $5.8 \%, p=0.007)$, and in both genders, the use of illicit drugs was more frequent among victims of violence (Table 3 ).

Table 1 Prevalence of each type of violence reported by immigrants during the previous year, by gender

\begin{tabular}{lccc}
\hline Abuse & $\begin{array}{l}\text { Females } \\
\mathrm{n}(\%)\end{array}$ & $\begin{array}{l}\text { Males } \\
\mathrm{n}(\%)\end{array}$ & $p$ value \\
\hline Emotional & & & 0.511 \\
No & $326(88.6)$ & $301(90.1)$ & \\
Yes & $42(11.4)$ & $33(9.9)$ & 0.350 \\
Physical & & $31(9.3)$ & \\
No & $342(92.9)$ & & 0.599 \\
Yes & $26(7.1)$ & $331(99.1)$ & \\
Sexual & & $3(0.9)$ & \\
No & $362(98.4)$ & $6(1.6)$ & \\
Yes & &
\end{tabular}

Table 2 Description of the violent episodes among victimized participants, by gender

\begin{tabular}{|c|c|c|c|}
\hline & Females n (\%) & Males n (\%) & $p$ value \\
\hline \multicolumn{4}{|l|}{ Frequency } \\
\hline Once & $36(61.4)$ & $37(73.5)$ & \multirow[t]{3}{*}{0.083} \\
\hline Some times & $14(24.6)$ & $12(24.5)$ & \\
\hline Many times & $8(14.0)$ & $1(2.0)$ & \\
\hline \multicolumn{4}{|l|}{ Place where it occurs } \\
\hline Home & $31(54.4)$ & $13(26.5)$ & 0.005 \\
\hline Work & $11(19.3)$ & $11(22.4)$ & 0.811 \\
\hline School & $4(7.0)$ & $2(4.1)$ & 0.684 \\
\hline Public spaces & $7(12.3)$ & $20(40.8)$ & 0.001 \\
\hline Other spaces & $5(8.8)$ & $5(10.2)$ & 0.801 \\
\hline \multicolumn{4}{|l|}{ Perpetrator/offender } \\
\hline Intimate partner & $25(43.9)$ & $3(6.1)$ & $<0.001$ \\
\hline Relative & $10(17.5)$ & $7(14.3)$ & 0.792 \\
\hline Friend & $5(8.8)$ & $3(6.1)$ & 0.722 \\
\hline Co-worker & $6(10.5)$ & $9(18.4)$ & 0.276 \\
\hline Client & $2(3.5)$ & $1(2.0)$ & 0.650 \\
\hline Stranger & $10(17.5)$ & $14(28.6)$ & 0.245 \\
\hline Other & $6(10.5)$ & $10(20.4)$ & 0.008 \\
\hline \multicolumn{4}{|c|}{ Country where it occurred } \\
\hline Portugal & $43(75.4)$ & $30(61.2)$ & 0.142 \\
\hline Country of origin & $19(33.3)$ & $20(40.8)$ & 0.545 \\
\hline Other country & $1(1.8)$ & $3(6.1)$ & 0.506 \\
\hline \multicolumn{4}{|c|}{ Any episode required medical care } \\
\hline Yes & $19(34.5)$ & $13(28.9)$ & 0.667 \\
\hline
\end{tabular}

\section{Discussion}

This is the first study, to the best of our knowledge, which describes the experience of violence among immigrants in Portugal, a country that traditionally faced waves of emigration and only recently has become host to immigrants from different regions of the world.

Our results showed that approximately $15 \%$ of the participants reported being victims of violence in the past year. In fact, analyzing the frequency of violence regardless of type (all forms considered), male and female immigrants experienced the phenomenon with similar frequency, which seems to indicate that the status of being an immigrant is a major vulnerability per se. Given the demands, the stress or the pressure on migrants, they are highly susceptible to a host of factors that may result in conflicts.

Few studies have addressed the intimate partner violence among immigrants [23]. However, our results showed a marked gender difference in the intimate partner violence, with $7.1 \%$ of women and only $0.9 \%$ of men claiming to have been victims. Although general data on violence suggested that both men and women were vulnerable to violence 
Table 3 Socio-demographic characteristics, immigration status, length of stay and substance use, according violence types, by gender

\begin{tabular}{|c|c|c|c|c|c|c|c|c|}
\hline & \multicolumn{4}{|c|}{ Females } & \multicolumn{4}{|c|}{ Males } \\
\hline & $\mathrm{N}$ & $\begin{array}{l}\text { Emotional } \\
\mathrm{n}(\%)\end{array}$ & $\begin{array}{l}\text { Physical } \\
\mathrm{n}(\%)\end{array}$ & $\begin{array}{l}\text { Sexual } \\
\mathrm{n}(\%)\end{array}$ & $\mathrm{N}$ & $\begin{array}{l}\text { Emotional } \\
\mathrm{n}(\%)\end{array}$ & $\begin{array}{l}\text { Physical } \\
\mathrm{n}(\%)\end{array}$ & $\begin{array}{l}\text { Sexual } \\
\mathrm{n}(\%)\end{array}$ \\
\hline \multicolumn{9}{|l|}{ Age (years) } \\
\hline $18-24$ & 74 & $9(12.2)$ & $5(6.8)$ & $2(2.7)$ & 62 & $6(9.7)$ & 8 (12.9) & $1(1.6)$ \\
\hline $25-44$ & 202 & 27 (13.4) & $14(6.9)$ & $2(1.0)$ & 193 & $18(9.3)$ & $16(8.3)$ & $1(0.5)$ \\
\hline $45-70$ & 91 & $6(6.6)$ & $7(7.7)$ & $2(2.2)$ & 76 & $9(11.8)$ & $7(9.2)$ & $1(1.3)$ \\
\hline \multicolumn{9}{|l|}{ Education (y) } \\
\hline$<10$ & 175 & $19(10.9)$ & $16(9.1)$ & $3(1.7)$ & 141 & $11(7.8)$ & $18(12.8)$ & 0 \\
\hline $10-12$ & 109 & $10(9.2)$ & $6(5.5)$ & $2(1.8)$ & 113 & $13(11.5)$ & $6(5.3)$ & $1(0.9)$ \\
\hline$>12$ & 79 & $13(16.5)$ & $3(3.8)$ & $1(1.3)$ & 75 & $8(10.7)$ & $6(8.0)$ & $2(2.7)$ \\
\hline Region of origin & & & & & & & $* 0.001$ & \\
\hline Africa & 191 & $19(9.9)$ & $19(9.9)$ & $3(1.6)$ & 131 & $12(9.2)$ & $18(13.7)$ & $1(0.8)$ \\
\hline Brazil & 125 & 17 (13.6) & $5(4.0)$ & $2(1.6)$ & 140 & $13(9.3)$ & $4(2.9)$ & $1(0.7)$ \\
\hline Eastern Europe & 50 & $6(12.0)$ & $2(4.0)$ & $1(2.0)$ & 62 & 8 (12.9) & $9(14.5)$ & $1(1.6)$ \\
\hline \multicolumn{9}{|l|}{ Marital status } \\
\hline Married & 177 & $18(10.2)$ & $11(6.2)$ & $1(0.6)$ & 150 & $14(9.3)$ & $12(8.0)$ & $2(1.3)$ \\
\hline Single/divorced/widow & 190 & $24(12.6)$ & $15(7.9)$ & $5(2.6)$ & 184 & $19(10.3)$ & $19(10.3)$ & $1(0.5)$ \\
\hline \multicolumn{9}{|l|}{ Employment status } \\
\hline Unemployed & 148 & $13(8.8)$ & $13(8.8)$ & $3(2.0)$ & 119 & $17(14.3)$ & $19(16.0)$ & $1(0.8)$ \\
\hline Employed & 214 & $29(13.6)$ & $13(6.1)$ & $3(1.4)$ & 212 & $16(7.5)$ & $11(5.2)$ & $2(0.9)$ \\
\hline \multicolumn{9}{|l|}{ Self-perceived income } \\
\hline Insufficient & 207 & $27(13.0)$ & $19(9.2)$ & $4(1.9)$ & 171 & $20(11.7)$ & $23(13.5)$ & $3(1.8)$ \\
\hline Sufficient & 145 & $13(9.0)$ & $5(3.4)$ & $2(1.4)$ & 147 & $13(8.8)$ & $7(4.8)$ & 0 \\
\hline \multicolumn{9}{|l|}{ Immigration status } \\
\hline Legal & 289 & $33(11.4)$ & $23(8.0)$ & $5(1.7)$ & 232 & $28(12.1)$ & $22(9.5)$ & $2(0.9)$ \\
\hline $\begin{array}{l}\text { In process of regularization/ } \\
\text { undocumented }\end{array}$ & 69 & 8 (11.6) & $3(4.3)$ & $1(1.4)$ & 93 & $5(5.4)$ & $9(9.7)$ & $1(1.1)$ \\
\hline Length of stay (years) & & & $* 0.010$ & & & & & \\
\hline$<5$ & 136 & $14(10.3)$ & $6(4.4)$ & $2(1.5)$ & 144 & $14(9.7)$ & $10(6.9)$ & $2(1.4)$ \\
\hline $5-10$ & 113 & $14(12.4)$ & $5(4.4)$ & $2(1.8)$ & 106 & $12(11.3)$ & $8(7.5)$ & 0 \\
\hline$>10$ & 88 & $11(12.5)$ & $13(14.8)$ & $1(1.1)$ & 68 & $6(8.8)$ & $10(14.7)$ & $1(1.5)$ \\
\hline Tobacco use & & & & & & & $* 0.007$ & \\
\hline No & 289 & $28(9.7)$ & $19(6.6)$ & $3(1.0)$ & 206 & $18(8.7)$ & $12(5.8)$ & $1(0.5)$ \\
\hline Yes & 75 & $13(17.3)$ & $7(9.3)$ & $2(2.7)$ & 127 & $15(11.8)$ & $19(15.0)$ & $2(1.6)$ \\
\hline \multicolumn{9}{|l|}{ Alcohol use } \\
\hline No & 167 & $14(8.4)$ & $11(6.6)$ & $2(1.2)$ & 74 & $5(6.8)$ & $4(5.4)$ & $1(1.4)$ \\
\hline Yes & 197 & 27 (13.7) & 15 (7.6) & $3(1.5)$ & 258 & $28(10.9)$ & $27(10.5)$ & $2(0.8)$ \\
\hline Illegal drugs use & & $* 0.002$ & $* 0.010$ & & & $* \mathbf{0 . 0 5 0}$ & $* 0.004$ & *0.034 \\
\hline No & 355 & $36(10.1)$ & $23(6.5)$ & $5(1.4)$ & 292 & $26(8.9)$ & $22(7.5)$ & $1(0.3)$ \\
\hline Yes & 6 & $4(66.7)$ & $2(33.3)$ & 0 & 37 & 7 (18.9) & $9(24.3)$ & $2(5.4)$ \\
\hline
\end{tabular}

in the community, women more frequently experience domestic violence, as demonstrated in previous studies [9, 24]. Considering socio-cultural heterogeneity within immigrant populations, for at least some groups such gender differences could be in part explained by the immigration of the couple from patriarchal societies where it is expected that women have to obey their husbands [23]. In that case, immigration could potentially increase a woman's vulnerability to abuse by her isolation and expected subservience to her male partner [25]. Nevertheless, we cannot state that these violent practices were imported from the immigrant's own culture, because personal attitudes on violence were not explored in this study.

Violence in the work place is a common problem among immigrants $[4,5,7,8]$. Our results showed that it affects both men and women. We were unable to assess whether violence 
was perpetrated by peers or co-workers, by supervisors or employers. It is known that in the work place immigrants may experience different types of violence: they can be severely exploited, especially if undocumented [6] or they can suffer abuse or different forms of discrimination perpetrated by co-workers or employers. Our questionnaire did not inquire as to immigrants' attitudes toward violence, particularly, if they denounced the episodes. However, it is probable that immigrant victims remain silent about the abuse, and refrain from calling the police, going to the hospital, or seeking legal assistance [15]. Although we do not know if these victims lodged complaint with the police, our results showed that among victims more than $30 \%$ required medical care due to the violent episode. Since domestic violence is a crime, we would expect some action following the episode.

We found a positive association between violence and substance use such as tobacco, alcohol and illegal drugs. Those who smoked, who drank and used illicit drugs were more frequently victims of violence, and similar findings were shown in other studies [26, 27]. However, we should highlight that our study has a cross-sectional design which precludes determination of causality. It remains unclear if the use of substances is a strategy to coping with violence, or if it triggers the violent episode.

A particular limitation of this study needs to be acknowledged. A validated standardized instrument for violence assessment was not used and the questions concerning violence were specifically created for the study, by the authors, focusing only on the victimization experiences. The violence perpetrated was not investigated among these immigrants.

In using the snowball sampling method, the non-random recruitment of initial and subsequent participants can result in recruitment bias towards respondents who are willing to participate. However, the participants' socio-demographic profiles are in line with previous data on immigrant populations in Portugal [18].

In conclusion, violence is a frequent problem among both female and male immigrants living in Portugal, although with different gender patterns regarding the perpetrators and settings of abuse.

Acknowledgments This study has been financially supported by Fundação para a Ciência e a Tecnologia (IME/SAU-ESA/81760/ 2006). Sílvia Fraga has a $\mathrm{PhD}$ grant from Fundação para a Ciência e a Tecnologia (SFRH/BD/44408/2008). The authors are very grateful to the project team members António Carlos da Silva, Maria do Rosário Horta, Maria Helena Cargaleiro, Mário Carreira, Violeta Alarcão and Miguel Lemos.

\section{References}

1. Kasturirangan A, Krishnan S, Riger S. The impact of culture and minority status on women's experience of domestic violence. Trauma Violence Abuse. 2004;5(4):318-32.
2. Jureidini R. Trafficking and contract migrant workers in the Middle East. Int Migr. 2010;48(4):142-63.

3. Abu-habib L. The use and abuse of female domestic workers from Sri Lanka in Lebanon. Gend Dev. 1998;6(1):52-6.

4. Shah NM, Menon I. Violence against women migrant workers: issues, data and partial solutions. Asian Pac Migr J. 1997;6(1): $5-30$.

5. Cox D. The vulnerability of Asian women migrant workers to a lack of protection and to violence. Asian Pac Migr J. 1997;6(1): $59-75$.

6. McGuire S, Canales MK. Of migrants and metaphors: disrupting discourses to welcome the stranger. ANS Adv Nurs Sci. 2010; 33(2):126-42.

7. McDermott $S$, Lee CV. Injury among male migrant farm workers in South Carolina. J Commun Health. 1990;15(5):297-305.

8. Ayalon L. Evaluating the working conditions and exposure to abuse of Filipino home care workers in Israel: characteristics and clinical correlates. Int Psychogeriatr. 2009;21(1):40-9.

9. Prosman GJ, Jansen SJ, Lo Fo Wong SH, Lagro-Janssen AL. Prevalence of intimate partner violence among migrant and native women attending general practice and the association between intimate partner violence and depression. Fam Pract. 2011; 28(3):267-71.

10. Rodriguez R. Violence in transience: nursing care of battered migrant women. AWHONNS Clin Issues Perinat Womens Health Nurs. 1993;4(3):437-40.

11. Owoaje ET, Olaolorun FM. Intimate partner violence among women in a migrant community in southwest Nigeria. Int $\mathrm{Q}$ Commun Health Educ. 2005;25(4):337-49.

12. Huisman KA. Wife battering in Asian American communities. Identifying the service needs of an overlooked segment of the US population. Violence Against Women. 1996;2(3):260-83.

13. Jewkes RK, Levin JB, Penn-Kekana LA. Gender inequalities, intimate partner violence and HIV preventive practices: findings of a South African cross-sectional study. Soc Sci Med. 2003; 56(1):125-34.

14. Kim-Godwin YS, Fox JA. Gender differences in intimate partner violence and alcohol use among Latino-migrant and seasonal farmworkers in rural southeastern North Carolina. J Commun Health Nurs. 2009;26(3):131-42.

15. Kupiszewski M, Mattila $H$ (eds.) Addressing the irregular employment of immigrants in the European Union: between sanctions and rights. Budapest: International Organization for Migration (IOM) Regional Mission for Central and South Eastern Europe; 2008.

16. Dias SF, Severo M, Barros H. Determinants of health care utilization by immigrants in Portugal. BMC Health Serv Res. 2008;8:207.

17. Dias S, Gama A, Cortes M, de Sousa B. Healthcare-seeking patterns among immigrants in Portugal. Health Soc Care Community. 2011;19(5):514-21.

18. SEF(2010) Relatório de Actividades 2009-Imigração, Fronteiras e Asilo. Departamento de Planeamento e Formação do Serviço de Estrangeiros e Fronteiras, Lisboa.

19. Sadler GR, Lee HC, Lim RS, Fullerton J. Recruitment of hard-toreach population subgroups via adaptations of the snowball sampling strategy. Nurs Health Sci. 2010;12(3):369-74.

20. Magnani R, Sabin K, Saidel T, Heckathorn D. Review of sampling hard-to-reach and hidden populations for HIV surveillance. AIDS. 2005;19(Suppl 2):S67-72.

21. Deren S, Shedlin M, Decena CU, Mino M. Research challenges to the study of HIV/AIDS among migrant and immigrant Hispanic populations in the United States. J Urban Health. 2005;82(2 Suppl 3):iii13-25.

22. International Organization for Migration. International migration law: glossary on migration. Geneva: IOM; 2004. 
23. Guruge S, Khanlou N, Gastaldo D. Intimate male partner violence in the migration process: intersections of gender, race and class. J Adv Nurs. 2009;66(1):103-13.

24. Dias S, Quintal F. Cultural dynamics in mental and reproductive health of immigrant women. Eur J Public Health. 2008; 18(Suppl. 1): 48.

25. Raj A, Silverman J. Violence against immigrant women: the roles of culture, context, and legal immigrant status on intimate partner violence. Violence Against Women. 2002;8(3):367-98.
26. Martin SL, Gibbs DA, Johnson RE, Sullivan K, Clinton-Sherrod M, Walters JL, et al. Substance use by soldiers who abuse their spouses. Violence Against Women. 2010;16(11):1295-310.

27. Vitale $S$, van de Mheen D. Illicit drug use and injuries: a review of emergency room studies. Drug Alcohol Depend. 2006;82(1): $1-9$. 